\title{
Obstetrical outcome in gestational diabetes mellitus: a retrospective study
}

\author{
Anitha Aldur Manjappa ${ }^{1 *}$, Maya Menon ${ }^{1}$, Aruna Bholenath Patil ${ }^{2}$
}

\begin{abstract}
${ }^{1}$ Department of Obstetrics and Gynecology, ${ }^{2}$ Department of Community Medicine, ESIC Medical College and PGIMSR, Chennai, Tamil Nadu, India
\end{abstract}

Received: 29 November 2018

Accepted: 29 December 2018

*Correspondence:

Dr. Anitha Aldur Manjappa,

E-mail: dr_ani1999@yahoo.com

Copyright: () the author(s), publisher and licensee Medip Academy. This is an open-access article distributed under the terms of the Creative Commons Attribution Non-Commercial License, which permits unrestricted non-commercial use, distribution, and reproduction in any medium, provided the original work is properly cited.

\begin{abstract}
Background: Gestational diabetes mellitus (GDM) is associated with adverse maternal and fetal outcomes. Majority of the maternal complications associated with GDM have been decreasing nowadays, however the relative risk of development of perinatal complications remain higher in women with hyper glycaemia.

Methods: This retrospective study was conducted among 286 delivered pregnant women. The pregnant women were diagnosed as GDM by DIPSI diagnostic criterion. The study was performed to find the association of various risk factors with GDM occurrence and to assess the obstetrical outcome in the GDM and normoglycaemic women.

Results: Out of the 286 women, the proportion of women affected with GDM was $20.6 \%$. The onset of GDM was more common among women between 25-30year (62.7\%). GDM onset is increased when they had previous history of GDM and family history of diabetes. The obstetric complications were less common among GDM women (23.72\%). GDM women had increased rate of caesarean delivery $(69.5 \%)$ and induction of labour $(42.4 \%)$. The neonatal complications were more common among GDM neonates $(57.62 \%)$. The proportion of occurrence of congenital anomalies and macrosomia ( $>3.5 \mathrm{~kg}$ ) was similar among both groups.

Conclusions: Risk factors associated with GDM onset such as previous history of GDM and family history of diabetes are significant risk factors. Advanced age, increasing parity and occurrence of abortions were not associated with GDM onset. With good glycaemic control the obstetrical complications and macrosomia are preventable. Rate of Induction of labour, caesarean delivery and neonatal morbidity remains higher among GDM women.
\end{abstract}

Keywords: DIPSI, Gestational diabetes mellitus, Macrosomia, Meal nutritional therapy

\section{INTRODUCTION}

GDM has been defined as any degree of glucose intolerance with onset or first recognition during pregnancy. ${ }^{1}$ Among the medical disorders which affect the pregnancy, Diabetes is one of the most common medical complications of pregnancy. It complicates two to five percent of pregnancies, of which $90 \%$ is contributed by Gestational Diabetes Mellitus (GDM). ${ }^{2}$

The prevalence of GDM varies, widely based on the diagnostic criteria used and the ethnic group studied. ${ }^{3}$ Among ethnic groups in South Asian countries, Indian women have the highest frequency of GDM. ${ }^{4}$ It has been reported that prevalence of GDM is almost 11-fold higher in Indian women when compared to the Caucasian population. ${ }^{5}$ GDM development is associated with the occurrence of impaired glucose tolerance (IGT) within a given population. A study by ICMR-INDiab estimated the prevalence of IGT between $8.3-14.6 \% .^{6}$ It has been reported that because of high prevalence of IGT among Indian population, there is a proportionate increase in the occurrence of GDM. ${ }^{7,8}$

Glucose intolerance is associated with adverse maternal and fetal outcomes. It has been observed that women with 
history of GDM and their offspring are at risk of developing diabetes in future. ${ }^{9,10}$ Therefore there is a definite need of universal screening for GDM for an early detection which helps in proper monitoring and treatment of the disease so as to prevent the complications associated with it.

The conventional methods so far used to diagnose GDM are as per country specific guidelines. DIPSI (Diabetes in Pregnancy Study group of India)-a modified WHO criteria was designed as per the Indian standards. It is simple, convenient and can be used as a universal screening test irrespective of meal time but having low sensitivity and is affected by diurnal variation. ${ }^{11-15}$

Recently a study by Srinivasan et al concluded that DIPSI criterion can be applied in low resource countries as it is easy and cost effective. ${ }^{16}$ Majority of obstetrical complications associated with GDM have been decreasing since 1980's due to increased awareness and appropriate multidisplinary antenatal care however the relative risk of development of perinatal complications remains 3 fold higher. ${ }^{15}$ A study by Jadhav et al in 2017 observed that decreased incidence of maternal complications like preeclampsia and preterm birth in GDM women but observed increased incidence of macrosomia despite well glycaemic control. ${ }^{17}$ The present study has been done to assess the maternal and fetal outcome in women diagnosed as GDM.

\section{METHODS}

This retrospective study was conducted in the ESIC Medical College and PGIMSR, Chennai for a period of 6 months from January 2016 to June 2016. Primary objective was to know the proportion of GDM occurrence among pregnant women delivered during the study period. Secondary objective was to find the association of risk factors with GDM occurrence and to assess the obstetrical and neonatal outcome among GDM and normoglycaemic women

\section{Inclusion criteria}

- All the pregnant women delivered in the institute during study period were included.

\section{Exclusion criteria}

- $\quad$ Pregnant women with preexisting Type 1 and Type 2 DM were excluded from the study.

Being a retrospective study, the details regarding maternal demographic characters, obstetrical and neonatal outcome were recorded from the medical records. All pregnant women were diagnosed as GDM by DIPSI diagnostic criterion. Pregnant women were given $75 \mathrm{~g}$ anhydrous glucose in $250-300 \mathrm{ml}$ water irrespective of last meal status. Plasma glucose estimation from venous blood sample was measured after 2 hours and plasma glucose values of $\geq 140 \mathrm{mg} / \mathrm{dl}$ was considered diagnostic of GDM. ${ }^{18}$ After the diagnosis was made, initial advice regarding Medical Nutrition Therapy (MNT) was given for 2 weeks. Insulin therapy was started when the FBS value reached $\geq 90 \mathrm{mg} / \mathrm{dl}$ and 2 hour PPPG value $\geq 120 \mathrm{mg} / \mathrm{dl}$. Pregnant women were carefully monitored throughout the pregnancy and followed up till delivery. At each visit all pregnant women were monitored for the early detection of obstetrical complications by means of clinical examination, biochemical and radiological investigations. GDM women on MNT and medical therapy having well controlled sugars were planned for termination of pregnancy at 40 completed weeks while GDM women with high dose of insulin and uncontrollable sugars were planned for termination of pregnancy depending on the clinical condition. Induction of labour was performed with cerviprime and oxytocin. During labour pregnant women were carefully monitored and active management of labour done. Caesarean section was performed for obstetrical indications. Routine postnatal sugar monitoring was done.

\section{Statistical analysis}

Categorical data were presented as numbers and percentages while, continuous data were expressed as mean \pm standard deviation (SD). An association between various attributes and GDM, Pearson Chi square test has been used. The Statistical significance was considered at $\mathrm{p}<0.05$. The analyses were performed using SPSS statistical software (version 21.0). The graphics were provided by Microsoft excel.

\section{RESULTS}

There were 301 deliveries during study period. 6 pregnant women had type 2 diabetics and were excluded. 9 case records had incomplete data. Totally 286 pregnant women were included for the study. Among them 59(20.6\%) were diagnosed as GDM according to DIPSI criteria and 227 (79.4\%) were normoglycaemics. It is depicted in Figure 1.

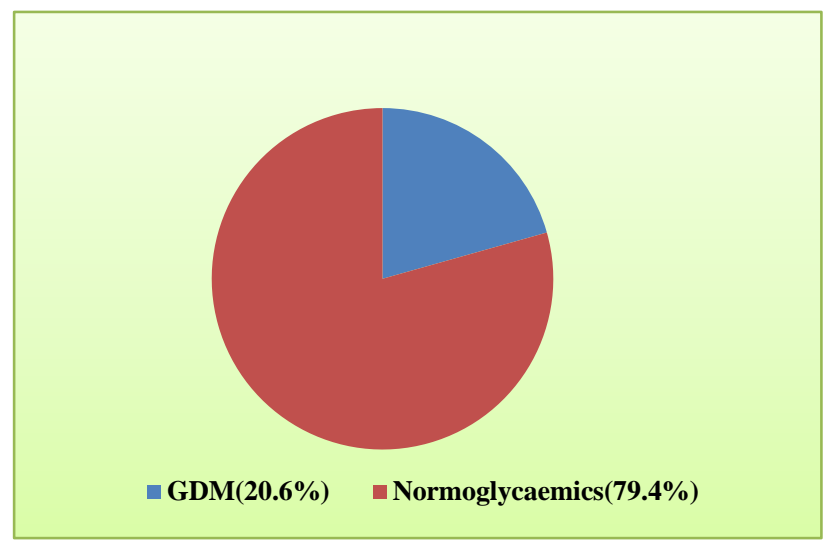

Figure 1: Proportion of GDM and normoglycaemics in the study population. 
GDM onset is associated with various factors such as age, parity, BMI, pervious history of GDM and family history of diabetes. In the present study all above factors were studied, however due to unavailability of BMI details, its association in development of GDM was not analysed. Among 286 women, majority of them the women were aged between 25-30years accounting to $163(57 \%)$ women. Among 44 women (15.4\%) who were $\geq 31$ years, $11(25 \%)$ women had GDM, while $33(75 \%)$ women were normoglycaemic throughout the pregnancy. In our study the onset of GDM was seen more common among women between 25-30year age group (62.7\%) compared to $18.6 \%$ women who were $\geq 31$ years $(p=0.321)$ (Table $1)$.

Table 1: Association of Age with GDM occurrence.

\begin{tabular}{|l|l|l|l|}
\hline $\begin{array}{c}\text { Age } \\
\text { (years) }\end{array}$ & GDM n-59 & $\begin{array}{l}\text { Non GDM } \\
\text { n-227 }\end{array}$ & \begin{tabular}{l} 
Total n-286 \\
\hline $19-24$
\end{tabular} \\
\hline & 11 & 68 & 79 \\
\hline & $13.9 \%$ & $86.1 \%$ & $100 \%$ \\
\hline $25-30$ & $37.6 \% *$ & $30.0 \% *$ & $27.6 \% *$ \\
\hline & $22.7 \%$ & $77.3 \%$ & 163 \\
\hline & $62.7 \% *$ & $55.5 \% *$ & $57.0 \% *$ \\
\hline$\geq 31$ & 11 & 33 & 44 \\
\hline & $25 \%$ & $75 \%$ & $100 \%$ \\
\hline & $18.6 \% *$ & $14.5 \% *$ & $15.4 \% *$ \\
\hline Total & $59(100)^{*}$ & $227(100) *$ & $286(100)^{*}$ \\
\hline *column percentages & & \\
\hline
\end{tabular}

Among 59 GDM women, 17 (28.8\%) had previous history of one or more abortions. The occurrence of one or more abortions among normoglycaemic women was $24.2 \%$. It implies that history of one or more abortions was not associated with the occurrence of GDM. $(\mathrm{p}=0.470)($ Table 2$)$.

Table 2: Association of abortion with GDM occurrence.

\begin{tabular}{|l|l|l|l|}
\hline Abortion & GDM n-59 & $\begin{array}{l}\text { Non GDM } \\
\text { n-227 }\end{array}$ & $\begin{array}{c}\text { Total } \\
\text { n-286 }\end{array}$ \\
\hline Yes & 17 & 55 & 72 \\
\hline & $23.6 \%$ & $76.4 \%$ & $100.0 \%$ \\
\hline & $28.8 \% *$ & $24.2 \% *$ & $25.2 \% *$ \\
\hline No & 42 & 172 & 214 \\
\hline & $19.6 \%$ & $80.4 \%$ & $100.0 \%$ \\
\hline & $71.2 \% *$ & $75.8 \% *$ & $74.8 \% *$ \\
\hline Total & $59(100 \%)^{*}$ & $227(100 \%)^{*}$ & $286 *$ \\
\hline *column percentages & & \\
\hline
\end{tabular}

In the present study, 139(48.6\%) were primigravida and $147(51.4 \%)$ were multigravida women. Occurrence of GDM among primigravida and multigravida women was $22.3 \%$ and $19.0 \%$ respectively. The occurrence of GDM among primigravida and multigravida was not statistically significant. $(\mathrm{p}=0.497)$. This is illustrated in the Table 3 . In the present study, $33(11.5 \%)$ women had previous history of GDM. Among them, 23 (69.7\%) women developed recurrent GDM in the present pregnancy while $10(30.3 \%)$ women did not develop GDM in spite they had previous history of GDM.

Table 3: Association of parity with GDM occurrence.

\begin{tabular}{|c|c|c|c|}
\hline Parity & $\begin{array}{l}\text { GDM } \\
\mathrm{n}-59\end{array}$ & $\begin{array}{l}\text { Non GDM } \\
\text { n-227 }\end{array}$ & $\begin{array}{l}\text { Total } \\
\text { n-286 }\end{array}$ \\
\hline \multirow[t]{3}{*}{ Primi } & 31 & 108 & 139 \\
\hline & $22.3 \%$ & $77.7 \%$ & $100.0 \%$ \\
\hline & $52.5 \% *$ & $47.6 \% *$ & $48.6 \% *$ \\
\hline \multirow{3}{*}{$\begin{array}{l}\text { Multi } \\
\text { (one or } \\
\text { more }\end{array}$} & 28 & 119 & 147 \\
\hline & $19.0 \%$ & $81.0 \%$ & $100.0 \%$ \\
\hline & $47.5 \% *$ & $52.4 \% *$ & $51.4 \% *$ \\
\hline Total & $59(100 \%)^{*}$ & $227(100 \%)^{*}$ & $286(100 \%)^{*}$ \\
\hline
\end{tabular}

This implies that rate of recurrent GDM increases in women with previous history of GDM $(p=.000)$. This is illustrated Table 4.

Table 4: Association of previous history with GDM occurrence.

\begin{tabular}{|l|l|l|l|}
\hline $\begin{array}{l}\text { Past } \\
\text { history }\end{array}$ & GDM n-59 & $\begin{array}{l}\text { Non GDM } \\
\text { n-227 }\end{array}$ & $\begin{array}{l}\text { Total } \\
\text { n-286 }\end{array}$ \\
\hline Yes & 23 & 10 & 33 \\
\hline & $69.7 \%$ & $30.3 \%$ & $100.0 \%$ \\
\hline & $39.0 \% *$ & $4.4 \% *$ & $11.5 \% *$ \\
\hline No & 36 & 217 & 253 \\
\hline & $14.2 \%$ & $85.8 \%$ & $100.0 \%$ \\
\hline & $61.0 \%$ & $95.6 \%$ & $88.5 \%$ \\
\hline Total & $59(100 \%)^{*}$ & $227(100 \%)^{*}$ & $286(100 \%)^{*}$ \\
\hline
\end{tabular}

*column percentages

Among 59 GDM women, 34 (57.6\%) had family history of diabetes. while the same was $53(23.3 \%)$ in non GDM women. This implies that occurrence of GDM was associated with a family history of diabetes and this was significant $(\mathrm{p}=0.00)$. This is illustrated in Table 5. Among the GDM women, Insulin therapy was required in 26 $(44.1 \%)$ women while the remaining $33(55.9 \%)$ required meal nutrition therapy along with life style modification.

Table 5: Association of family history with GDM occurrence.

\begin{tabular}{|l|l|l|l|}
\hline $\begin{array}{l}\text { Family } \\
\text { history }\end{array}$ & GDM & $\begin{array}{l}\text { Non GDM } \\
\text { N-227 }\end{array}$ & Total N-286 \\
\hline Yes & 34 & 53 & 87 \\
\hline & $39.1 \%$ & $60.9 \%$ & $100.0 \%$ \\
\hline & $57.6 \% *$ & $23.3 \% *$ & $30.4 \% *$ \\
\hline No & 25 & 174 & 199 \\
\hline & $12.6 \%$ & $87.4 \%$ & $100.0 \%$ \\
\hline & $42.4 \%$ & $76.7 \%$ & $69.6 \% *$ \\
\hline Total & $59(100 \%)^{*}$ & $227(100 \%)^{*}$ & $286(100 \%)^{*}$ \\
\hline
\end{tabular}

*column percentages 
In the present study medical complications were observed in $64(22.37 \%)$ women. Most common complication was Hypothyroidism found in $31(10.83 \%)$ women followed by Anaemia in $24(8.39 \%)$ women and others constituted to affect $7(2.44 \%)$ women. Among the other complications, it was found that $1(1.7 \%)$ women had Atrial septal defect in GDM category and $6(2.64 \%)$ women were affected (Epilepsy in 4, Bronchial asthma in one and Protein S deficiency in one) in the non GDM category.

The medical complications affected $16(27.11 \%)$ of the GDM and $48(21.14 \%)$ of the non GDM women. However increased occurrence of medical complications among GDM women was not statistically significant in the present study. $(\mathrm{p}=0.702)$. This is shown in Table 6 .

Table 6: Association of medical complications with GDM.

\begin{tabular}{|l|l|l|l|}
\hline & $\begin{array}{l}\text { GDM } \\
\mathrm{n}-59(\%)\end{array}$ & $\begin{array}{l}\text { NON GDM } \\
\mathrm{n}-227(\%)\end{array}$ & $\begin{array}{l}\text { Total } \\
\mathrm{n}-286(\%)\end{array}$ \\
\hline Anemia & $7(11.9)$ & $17(7.48)$ & $24(8.39)$ \\
\hline Hypothyroidism & $7(11.9)$ & $24(10.57)$ & $31(10.83)$ \\
\hline $\begin{array}{l}\text { Chronic } \\
\text { hypertension }\end{array}$ & $1(1.7)$ & $1(0.44)$ & $2(0.69)$ \\
\hline $\begin{array}{l}\text { Others } \\
\text { Total } \\
\text { complications }\end{array}$ & $1(1.7)$ & $6(2.64)$ & $7(2.44)$ \\
\hline
\end{tabular}

In the present study, $78(27.27 \%)$ women had one or the other pregnancy specific complications. PROM was the most common complication found in 32 (11.18\%) women followed by Oligohydramnnios in $28(9.8 \%)$ women while $11(3.84 \%)$ and $4(1.4 \%)$ women had Preeclampsia and polyhydramnios respectively. Other complications namely placenta previa, hydrocephalus and intrauterine death was noticed in $3(1.04 \%)$ women, who were of non GDM category.

The occurrence of obstetric complications were more commonly noticed among normoglycaemic women 64 (28.19\%) whereas GDM women 14 (23.72\%) had decreased occurrence of pregnancy complications. $(\mathrm{p}=0.789)$. This is illustrated Table 7.

Table 7: Obstetric complications associated with GDM.

\begin{tabular}{|l|l|l|l|} 
& $\begin{array}{l}\text { GDM } \\
\text { n-59 }(\%)\end{array}$ & $\begin{array}{l}\text { NON GDM } \\
\text { n-227 }(\%)\end{array}$ & $\begin{array}{l}\text { Total } \\
\text { n-286 }(\%)\end{array}$ \\
\hline PROM & $6(10.16)$ & $26(11.45)$ & $32(11.18)$ \\
\hline $\begin{array}{l}\text { Oligo- } \\
\text { hydramnnios }\end{array}$ & $4(6.77)$ & $24(10.57)$ & $28(9.8)$ \\
\hline Preeclampsia & $3(5.08)$ & $8(3.52)$ & $11(3.84)$ \\
\hline Polyhydramnios & $1(1.7)$ & $3(1.32)$ & $4(1.4)$ \\
\hline Others & 0 & $3(1.32)$ & $3(1.04)$ \\
\hline Total & $14(23.72)$ & $64(28.19)$ & $78(27.27)$ \\
\hline
\end{tabular}

Among 59 GDM women, 25 (42.4\%) required induction of labor while $9(15.3 \%)$ had spontaneous onset of labour. In normoglycemic women, 79 (34.8\%) required induction of labour and $71(31.3 \%)$ had spontaneous labour. The association of need for labour induction, occurrence of spontaneous labour and direct caesarean section in GDM women showed statistically just significant $(\mathrm{p}=050)$ (Table 8$)$.

Table 8: Mode of onset of labour.

\begin{tabular}{|l|l|l|l|}
\hline $\begin{array}{l}\text { Mode of onset of } \\
\text { labour }\end{array}$ & $\begin{array}{l}\text { GDM } \\
\text { n-59 }(\%)\end{array}$ & $\begin{array}{l}\text { NON } \\
\text { GDM } \\
\text { n-227 }(\%)\end{array}$ & $\begin{array}{l}\text { Total } \\
\text { n-286 }(\%)\end{array}$ \\
\hline Spontaneous labour & 9 & 71 & 80 \\
\hline & 11.3 & $88.8 \%$ & 100.0 \\
\hline Induced & $15.3^{*}$ & $31.3 \% *$ & $28.0^{*}$ \\
\hline & 25 & 79 & 104 \\
\hline Direct LSCS & 24.0 & $76.0 \%$ & 100.0 \\
\hline & $42.4^{*}$ & $34.8 \% *$ & $36.4^{*}$ \\
\hline & 25 & 77 & 102 \\
\hline Total & 24.5 & $75.5 \%$ & 100.0 \\
\hline & $42.4^{*}$ & $33.9 \% *$ & $35.7^{*}$ \\
\hline
\end{tabular}

*column percentages

In the present study, over all caesarean section rate stood up to $59.4 \%$. The rate of caesarean section and vaginal delivery in GDM women were was $69.5 \%$ and $30.5 \%$ respectively whereas the rate of caesarean section and vaginal delivery in Non GDM women were $56.8 \%$ and $43 \%$ respectively.

In the present study GDM women had increased occurrence of caesarean section up to $69.5 \%$. It was statistically significant. ( $\mathrm{p}=0$.042) (Figure 2).

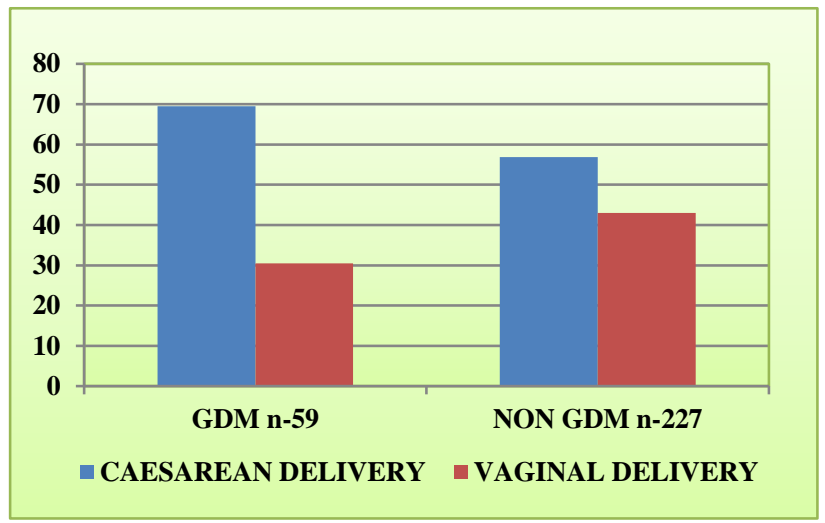

Figure 2: Mode of delivery in the study population.

As already mentioned, in the present study 170 (59.4\%) women required caesarean section. The higher rate of caesarean section was due to post caesarean pregnancy with doubtful scar in $73(42.94 \%)$ women followed by fetal distress in $24(14.11 \%)$ women. 
The proportion of women requiring caesarean section due to failed induction was $8(13.55 \%)$ in GDM women when compared to $9(3.96 \%)$ in non GDM women (Table $9)$. In the present study $13(4.54 \%)$ women had one or another maternal morbidity. PPH was most common complication affecting $6(2.09 \%)$ women followed by wound infection in $5(1.74 \%)$ women.

Table 9: Indication for caesarean section.

\begin{tabular}{|l|l|l|l|}
\hline $\begin{array}{l}\text { Indication for } \\
\text { caesarean section }\end{array}$ & N-59 & $\begin{array}{l}\text { Non GDM } \\
\text { N-227 (\%) }\end{array}$ & $\begin{array}{l}\text { Total } \\
\text { N-286 }\end{array}$ \\
\hline Failed induction & $8(13.5)$ & $9(3.96)$ & 17 \\
\hline Fetal distress & 4 & 20 & $24(14.11)$ \\
\hline CPD & 2 & 19 & 21 \\
\hline $\begin{array}{l}\text { Post caesarean } \\
\text { pregnancy }\end{array}$ & $19(32.2)$ & $54(23.78)$ & $\begin{array}{l}73 \\
(42.94)\end{array}$ \\
\hline $\begin{array}{l}\text { Meconium } \\
\text { stained liquour }\end{array}$ & 3 & 9 & 12 \\
\hline $\begin{array}{l}\text { Breech } \\
\text { presentation }\end{array}$ & 2 & 10 & 12 \\
\hline $\begin{array}{l}\text { Others } \\
\text { Total }\end{array}$ & 3 & 8 & 11 \\
\hline
\end{tabular}

Febrile morbidity was observed in $2(3.38 \%)$ of GDM women. $8.47 \%$ of GDM women had maternal morbidity compared to $3.52 \%$ of normoglycaemic women. However, it was not statistically significant $(\mathrm{p}=0.136)$ (Table 10).

Table 10: Maternal morbidity in the study population.

\begin{tabular}{|l|l|l|l|}
\hline & GDM n-59 & $\begin{array}{l}\text { NON GDM } \\
\text { n-227 }\end{array}$ & Total n-286 \\
\hline PPH & $2(3.38)$ & $4(1.76)$ & $6(2.09)$ \\
\hline $\begin{array}{l}\text { Wound } \\
\text { infection }\end{array}$ & $1(1.69)$ & $4(1.76)$ & $5(1.74)$ \\
\hline $\begin{array}{l}\text { Maternal } \\
\text { fever }\end{array}$ & $2(3.38)$ & 0 & $2(0.69)$ \\
\hline Total & $5(8.47)$ & $8(3.52)$ & $13(4.54)$ \\
\hline
\end{tabular}

In the present study, majority of neonate $130(45.5 \%)$ weighed between $2.51-3 \mathrm{~kg}$ followed by $85(29.7 \%)$ neonate who weighed between $3.01-3.50 \mathrm{~kg}$. The proportion of neonate weighing more than $3.5 \mathrm{~kg}$ was $6.6 \%$.

The occurrence rate of macrosomia $(>3.5 \mathrm{~kg})$ was $8.5 \%$ among GDM women corresponding figure for normoglycaemics was $6.2 \%$. The occurrence of macrosomia among GDM women was not statistically significant $(\mathrm{p}=0.883)$. This is illustrated in Table 11 .

In the present study overall need for NICU admission was $43 \%$. Most common neonatal complication was RDS found in $45(15.73 \%)$ neonate followed by hyperbilirubinemia in $35(12.23 \%)$ neonate. Occurrence of congenital anomalies among GDM and non GDM women was $3.38 \%$ and $3.52 \%$ respectively. The neonatal complications which required NICU care was more common among GDM neonates accounting to $57.62 \%$. compared to non GDM neonates of about $38.76 \%$ $(\mathrm{p}=0.004)$. This is illustrated in Table 12 .

Table 11: Distribution of neonatal weight.

\begin{tabular}{|c|c|c|c|}
\hline & $\begin{array}{l}\text { GDM } \\
n-59\end{array}$ & $\begin{array}{l}\text { Non GDM } \\
\text { n-227 }\end{array}$ & $\begin{array}{l}\text { Total } \\
\text { n-286 }\end{array}$ \\
\hline \multirow[t]{3}{*}{$<2 \mathrm{~kg}$} & 2 & 4 & 6 \\
\hline & $33.3 \%$ & $66.7 \%$ & $100.0 \%$ \\
\hline & $3.4 \% *$ & $1.8 \% *$ & $2.1 \% *$ \\
\hline \multirow{3}{*}{$2.01-2.50 \mathrm{~kg}$} & $9 * * *$ & 37 & 46 \\
\hline & $19.6 \%$ & $80.4 \%$ & $100.0 \%$ \\
\hline & $15.3 \% *$ & $16.3 \% *$ & $16.1 \% *$ \\
\hline \multirow[t]{3}{*}{$2.51-3 \mathrm{~kg}$} & $25 * *$ & 105 & 130 \\
\hline & $19.2 \%$ & $80.8 \%$ & $100.0 \%$ \\
\hline & $42.4 \% *$ & $46.3 \% *$ & $45.5 \% *$ \\
\hline \multirow[t]{3}{*}{$3.01-3.50 \mathrm{~kg}$} & 18 & 67 & 85 \\
\hline & $21.2 \%$ & $78.8 \%$ & $100.0 \%$ \\
\hline & $30.5 \% *$ & $29.5 \% *$ & $29.7 \% *$ \\
\hline \multirow[t]{3}{*}{$>3.5 \mathrm{~kg}$} & 5 & 14 & 19 \\
\hline & $26.3 \%$ & $73.7 \%$ & $100.0 \%$ \\
\hline & $8.5 \% *$ & $6.2 \% *$ & $6.6 \% *$ \\
\hline Total & $59(100)$ & $227(100)$ & $286(100)$ \\
\hline
\end{tabular}

*column percentages, $* * *$ twins weighing 2 and $2.2 \mathrm{~kg} * *$ twins weighing 2.9 and $2.95 \mathrm{~kg}$

Table 12: Occurrence of neonatal complications.

\begin{tabular}{|l|l|l|l|}
\hline & $\begin{array}{l}\text { GDM } \\
\text { n-59 }\end{array}$ & $\begin{array}{l}\text { NON } \\
\text { GDM } \\
\text { n-227 }\end{array}$ & $\begin{array}{l}\text { Total } \\
\text { n-286 }\end{array}$ \\
\hline Hyperbilirubinemia & $11(18.64)$ & $24(10.57)$ & $35(12.23)$ \\
\hline RDS & $9(15.25)$ & $36(15.85)$ & $45(15.73)$ \\
\hline SGA/IUGR & $5(8.47)$ & $15(6.6)$ & $20(7)$ \\
\hline HIE & $2(3.38)$ & $2(0.88)$ & $4(1.39)$ \\
\hline Hypoglycemia & $4(6.77)$ & $1(0.44)$ & $5(1.74)$ \\
\hline Sepsis & $1(1.69)$ & $2(0.88)$ & $3(1.04)$ \\
\hline $\begin{array}{l}\text { Congenital } \\
\text { anomalies }\end{array}$ & $2(3.38)$ & $8(3.52)$ & $10(3.5)$ \\
\hline Total & $34(57.62)$ & $88(38.76)$ & $122(42.65)$ \\
\hline
\end{tabular}

\section{DISCUSSION}

In the study among 286 women, the proportion of women diagnosed with GDM was $20.6 \%$.Seshiah et al in their community based study in 2008 reported the prevalence of GDM of about $17.8 \%$ women in urban, $13.8 \%$ in semi urban and $9.9 \%$ in rural areas. ${ }^{19}$ The recent guidelines issued by the State Health Society and Directorate of Public Health and Preventive Medicine estimates the incidence of GDM to increase by $20 \% .^{20}$ In our study mean age in study population was $26.951 \pm 3.5744$. The proportion of women affected with GDM was more common in the age group of $25-30$ years $(62.7 \%)$. Similar findings were found by recent researchers, they observed majority of GDM affected women were aged between 26- 
30 years. $^{21,22}$ In present study the occurrence of GDM among women $\geq 31$ years was $18.6 \%$. A study by Seshiah et al reported age more than 25 years is a risk factor for GDM. ${ }^{19}$ The occurrence of one or more abortions among GDM and normoglycaemics women was $28.8 \%$ and $24.2 \%$ respectively History of one or more abortions is not associated with the occurrence of GDM in present study $(\mathrm{p}=0.470)$. However, a study by Saxena et al reported previous history of abortions is a risk factor for GDM occurrence. ${ }^{23}$

In the present study $48.6 \%$ were primigravida and $51.4 \%$ were multigravida. Occurrence of GDM among primigravida and multigravida women was $22.3 \%$ and $19.0 \%$ respectively. Seshiah at al reported GDM occurrence among multigravida was $25.8 \%,{ }^{13}$ Rajput et al. shows that higher parity would have a higher rate of GDM occurence. ${ }^{24}$

In the present study, $69.7 \%$ women developed recurrent GDM. Above findings are comparable to $50 \%$ being reported by Seshiah et al. ${ }^{18}$ Suggests previous history of GDM is a risk factor for GDM occurrence.

In the present study, $57.6 \%$ women of GDM had family history of Diabetes. This is similar to the findings obtained by Joy et al, they observed $64.86 \%$ had family history, however a study done by Bhat et al and Seshaiah et al reported GDM occurrence of about $37.3 \%$ and $32.3 \%$ respectively for women who had family history of GDM. ${ }^{19,25,26}$

In the present study medical complications most commonly reported was anemia and hypothyroidism. Overall it affected $27.11 \%$ of GDM women and $21.14 \%$ of non GDM women. Saxena et al reported increased occurrence of hypothyroidism in women with hyperglycaemia. ${ }^{23}$ Similarly a study by Kadiyala et al reported occurrence of hypothyroidism was associated with hyperglycaemia. ${ }^{27}$

In the present study occurrence of obstetric complications like PROM, oligohydramnnios, preeclampsia and polyhydramnios were more common among normoglycaemic women $(28.19 \%)$ whereas GDM women has had decreased occurrence of obstetric complications $(23.72 \%)$. It was comparable to findings reported by Jadhav et al. ${ }^{17}$ This may be due to early diagnosis and prompt multidisplinary management of GDM women with lifestyle modifications and accurate glycemic control by medical therapy.

Among GDM women, rate of induction of labour was $42.4 \%$. In normoglycaemic women $34.8 \%$ required induction of labour. A study by Sathiamma et al. observed need for induction of labour for about $37.2 \%$ among GDM women. ${ }^{28}$ The rate of caesarean section and vaginal delivery in GDM women was $69.5 \%$ and $30.5 \%$ respectively whereas among non GDM women $56.8 \%$ underwent caesarean section and $43 \%$ had vaginal delivery. This It implies that there is increased occurrence of caesarean section in GDM women. , comparable to findings reported by Saxena et al. They reported that $71.4 \%$ of hyperglycaemic women required caesarean section. $^{23}$

Occurrences of maternal complications like post-partum haemorrhage, fever and wound infection was $8.47 \%$ in GDM women when compared to $3.52 \%$ in normoglycaemic women. However, it was not statistically significant.

In the present study there was no neonatal death. The occurrence of neonatal complications which required NICU care was more common among GDM neonates accounting to $57.62 \%$ compared to non GDM neonates of about $38.76 \%$. In the present study .Neonatal complications were more common among GDM women. Similar results were obtained by Saxena et al. ${ }^{23}$ Jadhav et al reported $33.75 \%$ of neonatal complications. ${ }^{17}$

The occurrence of congenital anomalies among GDM women was $3.38 \%$. In normoglycaemics women it was $3.52 \%$. The proportion of occurrence of congenital anomalies between GDM and normoglycaemics women was same. Similar observations has been observed by Jadhav et al. ${ }^{17}$

In the present study, majority of neonate $(45.5 \%)$ were weighing between $2.51-3 \mathrm{~kg}$ followed by $29.7 \%$ neonate who were weighing between $3.01-3.50 \mathrm{~kg}$.

The proportion of neonate weighing more than $3.5 \mathrm{~kg}$ among GDM was $8.5 \%$. It was comparable to results obtained by Wahi et al. ${ }^{29}$ Sathiamma et al observed macrosomia in about $2.9 \%$ of neonates delivered by GDM mother. ${ }^{28}$

\section{CONCLUSION}

Indian population have inherent tendency to develop diabetes and in turn GDM. DIPSI- modified WHO criteria designed as per Indian standards, which is an easy, cost effective and recommended by recent researchers has been used for GDM screening in our study population.

Risk factors associated with GDM occurrence such as previous history of GDM and family history of diabetes remains the significant risk factors. Advanced age, increasing parity and occurrence of one or more abortions was not associated with GDM onset. GDM women had associated increased medical complications (27.11\%) however with good glycaemic control the proportion of women affected with obstetrical complications were less $(23.72 \%)$. The occurrence of macrosomia and congenital anomalies among both groups was similar. Rate of Induction of labour (42.4\%), caesarean delivery $(69.5 \%)$ and neonatal morbidity $(57.62 \%)$ remains higher among GDM women. 


\section{ACKNOWLEDGMENTS}

Authors would like to thank Dr. Santhoshini and staff of Medical Records Department for their support during the study.

Funding: No funding sources

Conflict of interest: None declared

Ethical approval: The study was approved by the Institutional Ethics Committee

\section{REFERENCES}

1. Metzger BE. Organizing committee: Summary and recommendations of the third international workshop conference on gestational diabetes mellitus. Diab.1991;40S2:197-201.

2. Report of the Expert Committee on the Diagnosis and Classification of Diabetes Mellitus. Diabetes Care 1997;20(7):1183-97.

3. International Diabetes Federation. IDF Diabetes Atlas, 6th edn. Brussels, Belgium: International Diabetes Federation, 2013. Available at https://www.idf.org/e-library/epidemiologyresearch/diabetes-atlas/19-atlas-6th-edition.html.

4. Beischer NA, Oats JN, Henry OA, Sheedy MT, Walstab JE. Incidence and severity of gestational diabetes mellitus according to country of birth in women living in Australia. Diab 1991:40(2):35-8.

5. Madsen JK, Haunsoe S, Helquit S, Hommel E, Malthe I, Pedersen NT, et al. Prevalence of hyperglycemia and undiagnosed diabetes mellitus in patients with acute myocardial infarction. Acta Med Scand. 1986;220(4):329-32.

6. Anjana RM, Pradeepa R, Deepa M, Datta M, Sudha $\mathrm{V}$, Unnikrishnan $\mathrm{R}$, et al. revalence of diabetes and prediabetes (impaired fasting glucose and/or impaired glucose tolerance) in urban and rural India: Phase I results of the Indian Council of Medical Research-INdia DIABetes (ICMR-INDIAB) study. Diabetol. 2011;54(12):3022-7.

7. Yogev Y, Haroush AB, MosheHod. Pathogenesis of gestational diabetes mellitus; Textbook of Diabetes and Pregnancy: pg-46 In. Hillary King Epidemiology of glucose Intolerance and GDM in women of childbearing age. Diabetes Care. 1998;21:B9-13.

8. Hedderson MM, Darbinian JA, Ferrara A. Disparities in the risk of gestational diabetes by race-ethnicity and country of birth. Paediatr Perinat Epidemiol 2010;24(5):441-8.

9. Pettitt DJ, Baird HR, Aleck KA, Bennett PH, Knowler WC. Excessive obesity in offspring of Pima Indian women with diabetes during pregnancy. N Engl J Med 1983;308(5):242-5.

10. Kim C, Newton KM, Knopp RH. Gestational diabetes and the incidence of type 2 diabetes: A systematic review. Diabetes Care 2002;25(10):1862-8.
11. Polur H, Arora R, Bandela PV. A mini review on diagnostic criteria of gestational diabetes mellitus. J. Pharm Sci Res. 2015;7(8):538-41.

12. Sharma A, Gupta M, Alpana A. Comparison of diagnostic accuracy of two one step procedures for screening of gestational diabetes mellitus. Int $\mathbf{J}$ Reprod Contracept Obstet Gynecol.2015;4(1):81-85.

13. Seshiah V, Das AK, Balaji V. Gestational diabetes mellitus-guidelines. JAPI -DIPSI Guidelines. Gestational Diabetes Mellitus in India. JAssoc Physic of India. 2004;52:707-11.

14. Mohan V, Mahalakshmi MM, Bhavadharini B, Maheshwari K, Kaliyarasi G, Anjana RM, et al. Comparison of screening for gestational diabetes mellitus by oral glucose tolerance tests done in the non - fasting (random) and fasting states. Acta Diabetol. 2014;51(6):1007-13.

15. Shand AW, Bell J, McElduff A, Morris J, Roberts CL. Diabetes mellitus in pregnancy: a populationbased study of pre-gestational diabetes mellitus and gestational diabetes mellitus in New South Wales, Australia. Diabet Med. 2008;25(6):708-15.

16. Srinivasan S. Reddi RP. Comparative study of DIPSI and IADPSG criteria for diagnosis of GDM . Int $\mathbf{J}$ Reprod Contracept Obstet Gynecol. 2018;7(3):932-7.

17. Jadhav DS, Wankhede UN. Study of maternal, fetal and neonatal outcomes in patients with gestational diabetes mellitus in a tertiary care hospital. . Int $\mathbf{J}$ Reprod Contracept Obstet Gynecol. 2017;6(7):301420

18. Seshiah V, Das AK, Balaji V, Joshi SR, Parikh MN, Gupta S. Diabetes in Pregnancy Study Group. Gestational diabetes mellitus--guidelines. J Assoc Physicians India 2006;54:622-8.

19. Seshiah V, Balaji V, Balaji MS, Paneerselvam A, Arthi T, Thamizharasi M, et al. Prevalence of gestational diabetes mellitus in South India (Tamil Nadu) a community-based study. J Assoc Physic Ind. 2008;1(56):329-33.

20. Operational Guidelines - National Health Mission Tamil Nadu, Available at www.nrhmtn.gov.in/guideline/GDM.pdf

21. Dudhwadkar AR, Fonseca MN. Maternal and fetal outcome in gestational diabetes mellitus. Int $\mathbf{J}$ Reprod Contracept Obstet Gynecol. 2016;5(10):3317-21.

22. Priyanka. Maternal and foetal outcome in patients of gestational diabetes mellitus. Int J Reprod Contracept Obstet Gynecol. 2018;7(9):3831-6

23. Saxena P, Tyagi S, Prakash A, Nigam A, Trivedi SS. Pregnancy outcome of women with gestational diabetes in a tertiary level hospital of north India. Indian J Community Med. 2011;36(2):120-3.

24. Rajput R, Yadav Y, Nanda S, Rajput M. Prevalence of gestational diabetes mellitus and associated risk factors at a tertiary care hospital in Haryana. Indian J Med Res. 2013;137(4):728-33

25. Joy R, Sivakumar V. A Prospective Study on the Effect of Gestational Diabetes Mellitus on Maternal 
and Fetal Outcome. International Journal. 2012;3(3):345-51

26. Bhat M, Ramesha KN, Sarma SP, Sangeetha Menon SC, Kumar G. Determinants of gestational diabetes mellitus: A case control study in a district tertiary care hospital in south India. Int J Diabet Developing Countries. 2010;30(2):91.

27. Kadiyala R, Peter R, Okosieme OE. Thyroid dysfunction in patients with diabetes: Clinical implications and screening strategies. Int J Clin Pract 2010;64(8):1130-9.

28. Sathiamma PK, Karunakaran L.A prospective study on maternal and perinatal outcome of gestational diabetes mellitus. Int J Reprod Contracept Obstet Gynecol. 2017;6(7):2933-2938

29. Wahi P, Dogra V, Jandial K, Bhagat R, Gupta R, Gupta S, Wakhloo A, Singh J. Prevalence of gestational diabetes mellitus (GDM) and its outcomes in Jammu region. J Assoc Physicians India. 2011;59(4):227-30.

Cite this article as: Manjappa AA, Menon M, Patil AB. Obstetrical outcome in gestational diabetes mellitus: a retrospective study. Int J Reprod Contracept Obstet Gynecol 2019;8:552-9. 